\title{
Studies on Sustainable Development of Ecological Sports Tourism Resources and Its Industry
}

\author{
Pengfei Zhu (Corresponding author) \\ Beihai College of Beihang University, Beihai, Guangxi 536000, China \\ E-mail: bhuzhu@126.com
}

\begin{abstract}
Through the analysis of ecological sports tourism resources and its characteristics, we investigated the key ecological sports tourism resources from the angle of regional planning, industrialization programming, design and so on in the present paper and put forward novel countermeasure for sustainable development.
\end{abstract}

Keywords: Ecological sports tourism, Tourism industry, Sustainable development

\section{Introduction}

Modern Chinese physical education is the combination of western and traditional Chinese sports. From the angel of historical development, whether western or Chinese sports deriving from natural sports, are all the products of human production and survival development. Modern sports civilization is the human civilization of industrial revolution and cultural development, and similar to the environmental issues imposed by industrial revolution, also bring many new issues. Along with the enhancing cognition and investigation level of human being on resources and environment, the combination of ecological and social science make people consider the return of modern sports to nature and the construction of new sports ecological environment. Therefore, sports ecology has been a new research area promptly developing in and out of China at present. Research directions developed currently mainly includes: composition of sports ecological system, basic characteristics and development law, sports and environment, green Olympics, leisure sports and so on. All these fail to form a systematic and complete theory and method system for sports ecology. Some research areas on sports ecological resources, such as systematic investigation, scientific analysis, sustainable development utilization and so on, have not attracted great attention, and especially, research on sustainable development utilization have not been systematically and comprehensively developed.

With abundant ecological resources, protection and utilization of ecological resources have been paid more and more attention during the process of ecology construction by Chinese government. In china, resource base is profound for the investigation and development of multi-ethnic ecological sports, ecological tourism is required by more and more people of the whole society, and attention have been paid to investment and development of high-grade ecological tourism industry. All these resource dominance afford a wider development space for ecological sports tourism industrialization. Spontaneous mass sports activities have always been developed well, which offers an excellent mass basis for the investigation of sports ecology and industrialization construction. On such condition of resources, environment and market demand, by using theory and technology of ecology, in combination with industrial development requirement, investigation and study of ecological sports tourism resources is systematically undertaken in order to seek countermeasures for sustainable development of ecological sports tourism industry, offer novel insight into sports development, pave a new space for the comprehensive development of society and economy in China and protection and utilization of ecological environment, and promote coordinated development of society, economy and ecology. Therefore, ecological sports tourism industry will bring favorable benefits of society, economy and ecology(Zhu, 2001, PP. 13-15).

\section{Resource analysis of ecological sports tourism industry}

Ecological sports tourism industry resources mainly include: ecological sports tourism resources, ecological tourism resources and tourism industry resources.

Ecological sports tourism resources are ecological sports items resources which meet with the demand of increasing healthy consumption of human society with respect to sports, including traditional, ethnic sports items and so on, and historical and traditional culture resources covered by those items, with obvious ethnic characteristics and personality(Wang, 2005, PP. 29-31). Chinese traditional and ethnic sports items, with distinctive characteristics, are the non-negligible high quality historical and cultural heritage in the inheritance of Chinese history and culture. Cross-synthesis of subjects, such as ethnology, sports science, tourism science, ecology and so on, are essential for understanding the values of its resources. 
Through investigation on such resources and combination with Chinese reality, characteristic resource evaluation and development system of Chinese history and culture could be developed, followed by product or production of industrialization(Zheng, 2005, PP. 43-46).

Ecological tourism resources are the general designation of all resources with respect to natural ecological environment in tourism resources, and the natural environment and its historical cultural background tourists learn, taste and enjoy, namely natural ecological, social and historical cultural resources. All these resources possess natural attributes, such as distinctive regionality, seasonality and so on, and social culture attribute. Such resources could be independently developed into ecological resource industry, but in combination with ecological tourism resources could get mutual benefits and form a novel industrial feature.

Tourism industry resources are summation of industrialization resource, tourism and item management with respect to tourism. Different from the two resources mentioned above, it could not only rely on the basis of natural ecological, ecological sports, tourism resources and so on, but also be independent on those resources. It is a kind of soft management and industrialization resource, implementation security of socialization, economization and ecology for tourism items, products and industry, and hence possesses indispensable values similar to the above-mentioned resources.

\section{Regional planning of ecological sports tourism key resources}

Scientific comprehensive investigation and study on ecological sports resources has not been undertaken at present. The question how to recognize and understand scientifically and comprehensively the characteristics and dominance of regional ecological sports resources, appears to be a mainly obstacle to industrialization development of ecological sports resources. Through the application of modern technological means of $3 \mathrm{~S}$ (Remote sensing, geography information systems and global positioning systems) and mathematical statistics, in combination with requirement survey of ecological sports tourism resources, environmental capacity, carrying capacity, etc., sorts, quantity, scale, characteristic and so on of regional key resources was ascertained. Based on this, further in combination with theory and method of regional planning, advisable regional planning was undertaken in order to offer scientific basis for the development of ecological sports tourism industry and government decision making, which could not only guarantee the scientific development of ecological sports, but also avoid the waste and destruction of ecological sports resources during the process of development, gradually pave a sustainable way for ecological sports industry and thus promote harmonious development of regional society, economy, culture and ecology and bring forward good social, economic and ecological benefits(Zhao, 2006, PP. 90-94).

In order to implement sustainable development of ecological sports tourism industry, latest achievements in subjects, such as ecological science, sports science, tourism management science, etc., should be applied in this area, and an investigation system including resource investigation, resource evaluation and analysis, resource utilization planning and resource management should be established. Based on this, resource dominance of industrial management should be exerted well to achieve the values of resources under performance of integration and actualization. Due to vast territory, lots of nationalities and abundant historical cultural heritage in China, it is tough to ascertain the policy and strategies for sustainable development. In the first stage, a comprehensive survey should be undertaken about Chinese ecological sports tourism resources. On the basis of the survey, basic and key resources of regional ecological sports tourism were ascertained through scientific analysis, and regional industrial development planning should be undertaken on such resources(Song, 2005, PP. 75-78).

Regional development planning of ecological sports tourism industry mainly includes: (1) basic constitute, distribution charts and protection and utilization general planning of basic resources; (2) Characteristics, distribution charts and regional planning of key resources; (3) General planning of industrialization development; (4) Design and planning of regional industrialization item.

Establishing supporting industrial policy according to the requirement of resources and planning, is essential for ensuring healthy sustainable development of industry. Industrial policy includes: (1) Protection and utilization policy of basic resources; (2) Protection, utilization and special management policy of key resources; (3) Supporting and preferential policy of industrialization sustainable development; (4) Strengthening the cognition of resource value, science popularization and correlated policy of resource management.

\section{Planning and design of ecological sports tourism industry}

Any industrialization developments all carry out through specific project design and implementation, and hence scientific and normative industrialization project design and implementation management become important content and guarantee for sustainable development. Because industrial development require strong and powerful economic guarantee, industrialization planning and design sometimes have many contradictions. Actually, relationship among economic, ecological and social benefits is complementary to each other. Scientific planning and design could attenuate such contradictions. Therefore, it becomes paramount for the prospective of planning and design, science of project planning and design and concrete embodiment of technical progress achievement. Studies on subjects, such as ecological science, sports science, tourism 
management science, industrial economics and so on, should be successfully undertaken to realize its sustainability by planning and its enforceability and validity by planning and design.

Principles of planning and design: economic benefits priority, unification of economic and social benefits; Adaption to local conditions; Protection and reasonable exploitation of resource; Unified planning, highlighting key points and implementing step by step.

Objective and index system: Objective is to establish an ecological sports tourism item with good economic benefits, meanwhile pay attention to ecological and social benefits; Corresponding index system includes economic indices(ratio of output to input, progressive increment capability of economic benefits and so on); Ecological indices(green cover percentage, ecological recovery ability, suitable degree of resource protection and utilization, environmental quality, pollution control rate and so on); Social indices(healthy tour and healthy body and mind, public environmental awareness and resource consciousness, universal education of ecological environment protection science and so on ).

Objective feasibility analysis: such analysis is kind of technical feasibility assess in terms of planning and design of ecological sports tourism item industrialization development, including environmental evaluation, population evolution law analysis, ecological recovery ability, resource optimization, item optimization setup and construction and so on, and offer technical support and guarantee for industrial planning and design.

Item functional planning and design: according to the investigation, analysis and evaluation of ecological sports tourism resources, all kinds of resources are undertaken conceptual and functional planning with function optimization in light of the requirement of tourism item development, with attempts to enhance resource protection, decrease resource destruction, sufficiently exert resource values and offer insight into the subsequent specific item design.

Item design: according to functional planning, industrialization specific items are designed, including item design of key ecological sports tourism resources, optimal combination design of basic resource item, tourism function guarantee design, special item design for health, tour and leisure, novel item design such as science popularization, environmental protection education, etc. All these items become industrial chain and cluster after integrated development.

Guarantee measures for industrial development and item construction: it mainly includes establishing and perfecting management system guaranteed for industrial development and item construction; Industrial planning brought into social economy development planning and yearly development plan by local government, accomplishing fund input for supporting early construction, widening capital channels, inducing further input of social fund, guarantee input of development fund, taking macro-control; Strengthening environmental protection and unified supervision; Exerting effects of media and education to promote awareness of public participation; Relying on scientific and technological progress, protecting and guaranteeing for industrial development; Drawing supporting policies and regulations, management regulations and detailed rules for implementation for the practice of ecological sports tourism industry in terms of national law, regulations and rules; Intensifying international exchange and cooperation and so on.

\section{Countermeasure for sustainable development of ecological sports tourism industry}

Sustainable development theory and method system have been developed for many years, and formed into certain mode. Such mode promotes social development, but at the same time, not always satisfies the development requirement of specific industry and item. Therefore, novel insight into sustainable development of ecological sports tourism industry is essential, and this update embodies specific innovated thinking and countermeasure in development countermeasure. Previous studies conformed that, and hence the following several key innovations are used as main content of sustainable development countermeasure to construct and develop.

Novel protection and utilization of ecological sports tourism resources is essential according to the characteristics of ecological sports tourism industry. Innovation in this area is based on the investigation, analysis and evaluation of ecological sports tourism industry, facilitates understanding the heterogeneity and value generality of natural ecological resources, sports ecological resources, tourism resources and historical cultural resources, and constituting measures of resource protection and strategy of resource exploitation and utilization(Liu, 2005, PP. 17-19).

Ecological sports tourism industry contains subjects, such as ecology, sports, tourism, sociology, culture and so on, and refers to ecological industry, sports industry, tourism industry, etc. Due to segmentation of trap and block resulted from professional research and industrial development, it is tough to form a systematic research and development, which becomes a limiting factor significantly affecting sustainable development of this industry. Consequently, sustainable development of the industry should break traditional limitations, under the guidance of local government, organize and develop cooperations of trans-subject and industry units and talents, integrate multi-subjects theory and technology application achievement to guarantee smooth progress of industrialization.

The formation and development of an industry relies on the progress of science and technology. In light of the requirement of industrial development, ecological sports tourism science and its related frontier and interdisciplinary subjects should be established and developed. Only in this case, innovative development has its stamina. 
Due to vast territory, irregular distribution of resources, notable discrepancy in economy between eastern and western regions, as well as main ecological sports tourism resources distributed in central and western regions and minority areas where development of economy, science and technology is relatively backward, and talent resources is scarce, diversification of developing modes should be mainly adapt to the requirement of industrial development, and moreover, government, investors, talents and so on should be provided with novel idea and sustainable development notion, and cooperate with innovation planning and science construction to achieve sustainable development.

Taken together, ecological sports tourism industry already possesses a qualification for healthy industrial development. During the period of industrial development, it can be anticipated that it could result in the progress of science and technology and grandness of excellent professional talent team, and based on those, promote economy development, social progress and human ecological civilization, and exhibit a profound prospect for the industrial sustainable development.

\section{References}

Liu, F.Y. (2005). Sports ecotourism and the countermeasures for its sustainable development. Journal of Shenyang Physical Education Institute, 24(1):17-19.

Song, D.L. (2005). Exploitation on human resource of ecological sports tourism in southwest of Zhejiang province. China Sports Science and Technology, 42(4):75-78.

Wang, D.H. (2005). Exploitation on human resource of ecological sports tourism in southwest of Zhejiang province. Journal of Wuhan Institute of Physical Education, 38(1):29-31.

Zhao, Y.Y. (2006). Investigation and analysis of development of ecological sports in mount Tai tourism area. Journal of Taishan University, 28(6):90-94.

Zheng, X.X. (2005). Connotation and characteristics of ecology sports. Journal of Chengdu Sport University, 30(2), 43-46.

Zhu, P.F. (2001).Take advantage of resources and characters, construct ecological industry example in Zhuhai. Special Zone Economy, 145(2):13-15. 